\title{
Information Analytics for Healthcare Service Discovery
}

\author{
Lily Sun ${ }^{1 *}$, Mohammad Yamin², Cleopa Mushi ${ }^{1}$, Kecheng Liu ${ }^{3,4}$, \\ Mohammed Alsaigh ${ }^{2}$ and Fabian Chen $^{5}$ \\ ${ }^{1}$ School of Systems Engineering, University of Reading, UK \\ ${ }^{2}$ Department of Management Information Systems, Faculty of Economics and \\ Administration, King Abdulaziz University, Jeddah, Saudi Arabia \\ ${ }^{3}$ Henley Business School, University of Reading, UK \\ ${ }^{4}$ School of Information Management and Engineering, Shanghai University of \\ Finance and Economics, Shanghai, China \\ ${ }^{5}$ Royal Berkshire NHS Foundation Trust, Reading, UK
}

Submitted February 2014. Accepted for publication August 2014.

\begin{abstract}
The concept of being 'patient-centric' is a challenge to many existing healthcare service provision practices. This paper focuses on the issue of referrals, where multiple stakeholders, such as General Practitioners (GPs) and patients, are encouraged to make a consensual decision based on patients' needs. In this paper, we present an ontology-enabled healthcare service provision, which facilitates both patients and GPs in jointly deciding upon the referral decision. In the healthcare service provision model, we define three types of profiles which represent different stakeholders' requirements. This model also comprises a set of healthcare service discovery processes: articulating a service need, matching the need with the healthcare service offerings, and deciding on a best-fit service for acceptance. As a result, the healthcare service provision can carry out coherent analysis using personalised information and iterative processes that deal with requirements which change over time.
\end{abstract}

Keywords: healthcare service discovery, patient-centric healthcare, service optimisation, multicriteria analysis, stakeholder profiling, information analytics

\section{INTRODUCTION}

There is an increasing pressure from the National Health Service (NHS), UK, on healthcare organisations, such as primary care and secondary care, to reduce operational costs and respond to rapid changes in patient expectations within healthcare service provision [1]. One of the changes is in relation to engaging patients

*Corresponding Author: Lily Sun, PhD, University of Reading, Whiteknights, Reading RG6 6AY, UK. Phone: +441183788604. Email: lily.sun@reading.ac.uk. Other authors:myamin@kau.edu.sa, c.j.s.k.mushi@gmail.com, k.liu@reading.ac.uk,oalsaigh@kau.edu.sa,fabian.chen@royalberkshire.nhs.uk. 
with General Practitioners (GPs) from the primary care in the referral decision-making process. During the referral process, the patient can define their personal desires or preferences concerning which hospital they like to be referred to, and what health services they would like to experience. Traditionally, GPs were solely responsible for referrals, i.e., with a referral decision made, without a patient's input, entirely on the knowledge held by the individual GP. A new 'patient-centric' practice as proposed in this work facilitates a process that considers patient requirements, constraints and preferences, such as waiting time, facilities provided, level of care, and access to public transport. The referral process is informed by multiple types of knowledge, e.g., the national policy on healthcare services offered and their quality measured. The process will be checked against a set of service delivery criteria, e.g., that defined by SERVQUAL [2, 3, 4] and Care Quality Commission [5] for the healthcare services and for measuring these services. In order to facilitate both patients and GPs participation throughout the referral process, a mechanism is required that enables us to articulate and consolidate the referral requirements of all the stakeholders, leading to a joint referral decision.

A referral process involves a set of knowledge-intensive tasks that can define and analyse key factors. These tasks require input and interactions, which are ultimately performed by both patients and GPs. However, the current referral system is not catered for a patient-centred approach. In order to improve the quality of healthcare service provision, we introduce a new ontology-enabled healthcare service provision method which is capable of:1) capturing the patients' profiles which contain personal records including referral cases, the profile of healthcare service providers that describe a structure and environment of hospitals, and the profile of healthcare services that define medical and non-medical services provided by a hospital; 2) articulating a patient's healthcare service needs and formulating a referral case in the patient profile; 3) discovering the healthcare services offered by the hospitals that match the requirements specified in the defined referral case; and 4) ranking the matching candidates if more than one possible service is found, and identifying a best-fit choice of healthcare service. These functions are allowed for execution to enter any point of the referral process, because a patient sometimes adjusts the referral requirements before a firm choice is made.

The remainder of the paper is organised as follows: Section 2 introduces the related research background; in Section 3 a methodological design of the ontology model is described; the method is validated in Section 4, and application results are presented; the implication and limitations of our method are discussed with directions for further work in Section 5; and conclusions are drawn in Section 6.

\section{RELATED WORK}

\subsection{Definition of Service Quality and Measurements}

Service provision takes place between consumers and providers. Consumers usually prefer the required service to be delivered to meet their expectations $[6,7]$. Satisfaction is attained by the right service being provided to the right needs from the right provider $[4,8]$. To achieve this in the healthcare domain, it is crucial that 


\section{Table 1. Healthcare service criteria}

\begin{tabular}{|c|c|c|}
\hline Criterion & Parameter & Description \\
\hline Hospital sector & Healthcare category & $\begin{array}{l}\text { NHS public hospital or independent (private) } \\
\text { hospital }\end{array}$ \\
\hline \multirow{6}{*}{$\begin{array}{l}\text { Medical } \\
\text { requirements }\end{array}$} & Diagnosis & Patients' health problem for referral \\
\hline & Health condition & $\begin{array}{l}\text { Patients' medical condition expressed as acute or } \\
\text { non-acute }\end{array}$ \\
\hline & Severity & $\begin{array}{l}\text { Patients' health situation expressed as mild, } \\
\text { moderate or severe }\end{array}$ \\
\hline & Diagnosis type & Diagnosis needed for outpatient or inpatient \\
\hline & Specialist doctor & $\begin{array}{l}\text { The availability of specialist doctor for the } \\
\text { particular condition }\end{array}$ \\
\hline & Treatment type & Treatment administered \\
\hline \multirow[t]{7}{*}{ Quality assessment } & Provider rating & Overall performance \\
\hline & Mortality ratio & $\begin{array}{l}\text { A national priority standard for actual deaths vs. } \\
\text { expected death in a year }\end{array}$ \\
\hline & Cleanliness & $\begin{array}{l}\text { Hygiene and cleanliness to reduce risks of } \\
\text { hospital acquired infections }\end{array}$ \\
\hline & Care level & $\begin{array}{l}\text { Individualised attention, willingness to help } \\
\text { patients }\end{array}$ \\
\hline & Equipment & Up to date physical facilities \\
\hline & Reliability & $\begin{array}{l}\text { Accurate billing and performing service } \\
\text { dependably/accurately }\end{array}$ \\
\hline & Patient feedback & Views of previous patients of the service \\
\hline \multirow[t]{3}{*}{ Support services } & Parking facilities & Service to visitors who come with cars \\
\hline & Visiting hours & Visitors' entrance time \\
\hline & $\mathrm{A} \& \mathrm{E}$ & $\begin{array}{l}\text { Availability of accident \& emergency services, } \\
\text { e.g., ambulance }\end{array}$ \\
\hline Waiting policy & Duration & Waiting time policy to attend the appointment \\
\hline Medical charges & Cost & Cost of health service \\
\hline \multirow[t]{2}{*}{ Geo-location } & Town/city & The town/city where the service is offered \\
\hline & Distance & $\begin{array}{l}\text { How far from the patient to the service expressed } \\
\text { in miles, NHS policy requirement }\end{array}$ \\
\hline
\end{tabular}

healthcare knowledge is clearly represented and understood by various stakeholders (e.g., patients and GPs) $[9,10,11]$. Such healthcare knowledge should not only include medical competencies, but also non-medical competencies of the hospital, e.g., public ratings, organisational culture, and service quality. These may sometimes be more of interest to the patient.

SERVQUAL, CQC, and NHS define service quality guidelines for healthcare services. Based on these guidelines, a set of criteria, which relate to qualitative and quantitative service quality in non-medical competences, are described in Table 1. 


\subsection{Formalisms for Knowledge Representation}

Conceptualisation of domain knowledge allows us to represent a holistic view of the problem context $[12,13]$. Ontologies, which originate from theories in Artificial Intelligence and Software Engineering, are mainly adopted to contextualise what exists in reality [14]. By definition, ontology is a formal and explicit specification of a shared conceptualisation of a domain $[15,16]$. The central role of ontologies is to aid sharing the meaning of terms in a given domain. Ontologies are classified into two types: lightweight and heavyweight ontologies, according to their internal structure [17]. Lightweight ontologies focus on defining concepts, relationship between concepts and properties that describe concepts. A lightweight ontology is capable of representing the existence of things although it does not deal with why things exist and in which form they should exist. Heavyweight ontologies, on the other hand, bring in intensive use of axioms (i.e., constraints) between concepts, that enhance lightweight ontologies. Such ontology represents a static conceptualisation of the domain which enables embodiment of norms specifying patterns of behaviour.

Organisational Semiotics (OS), for example, provides heavyweight ontology modelling [15, 18, 19]. Key concepts used to devise an ontology model in Organisational Semiotics include:

- Agent (usually drawn as an ellipse in a graphical representation) represents a stakeholder who has responsibilities. An agent can be an individual, a group or community, such as society, nation, organisation, or person.

- $\quad$ Role is always associated with an agent that undertakes a specific responsibility. For example, a patient is the role of a person, and a service provider is the role of an organisation.

- Affordance (usually denoted in a rectangle in a graphic model) is a concept introduced to represent a repertoire of behaviour [20]. An affordance is ontologically dependent on its antecedents, which are placed on its left in the graphical model. For example, a person and an organisation jointly will be able to afford a certain repertoire of behaviour, such as employment (hence the affordance of employment). Meanwhile the affordance of employment can become an antecedent, as employment may afford further behaviour. Such an analysis continues until all concepts in the problem domain are identified.

- Generalisation (represented as a triangular arrowhead) refers to "a-kind-of" relationship between a generic agent and a more specific type of agent in a context. A specific agent inherits all the properties of the generic agent.

- A determiner (preceded with a \# in a graphic model) holds the descriptive information about the concept. For example, the concept of patient has determiners of \#name and \#address. Determiners can be used to characterise a profile [21, 22].

- Norm specifies a pattern of behaviour of an affordance in the following structure: wherever $<$ context $>$, if $<$ condition $>$, then $<$ agent $>$, is $<$ deontic operator $>$, to $<$ action>. A deontic operator is defined in Deontic Logic and holds one of the following values, i.e., obliged, permitted and prohibited. A deontic operator indicates the responsibility of the agent under the said context and condition. 


\subsection{Service Discovery and Computational Intelligence}

Service discovery is the process of finding services that matches the requirements of a service requestor [23]. From a technical perspective, service discovery, based on service profiles and profile matching, can automatically carry out relevant workflow to retrieve relevant services. Such a workflow, however, requires various types of information analysis and processing. A hybrid approach is proposed in this study, which incorporates the following methods and techniques.

Case-based reasoning (CBR) is a cognitive technique for problem solving, i.e., by reasoning and learning from past experiences. CBR is applied widely in the field of medicine, e.g., clinical diagnosis, classification, planning and tutoring, psychiatry and epidemiology [24], and has both the computational capability and pervasive behaviour to support human decision-making. CBR is also employed in the delivery of healthcare services, thus allowing a problem featuring patient satisfaction, cost control, quality maintenance and timeliness, to be reasoned towards a sound and justified solution [25]. As a complement to rule-based descriptions, CBR solves new problems based upon the solutions of similar past problems in the repository, and reuse the solution from the best problem match in the new situation. A case, $C^{I}$, with the extension, can be expressed by the concepts of \{(problem_feature, value, weight $)$, solution, feedback\} [13]. A weight, $w_{i}$, is assigned to each problem feature, $f_{i}$, by adopting the fundamental scale of 1-9 in pair-wise comparison analysis [26]. The $w_{i}$ value indicates how important $f_{i}$ is against $\left\{f_{1} \ldots f_{n}\right\}$ from a personalised perspective in $C^{I}$. A matching process carries out a number of tasks: 1) retrieve the most similar cases from a case-base, according to a problem specification of the new case; 2 ) reuse the solution of the mapped existing cases for the new case; 3 ) revise the solution of the new case for soundness and post the new case being tested in the real situation; and 4) retain the revised new case in the case-base for future matching. If no previous similar problem features are found in the existing case, the new case becomes the initial case and is subsequently retained in the case base.

Data Envelopment Analysis (DEA) and Analytic Hierarchy Process (AHP) are notably gaining popularity in the field of benchmarking of healthcare service performance $[27,28]$. DEA is a method that uses fractional and corresponding linear programmes to measure the relative performance of multiple decision-making units (DMUs) by aggregating input and output quantities [29, 30]. Performance efficiency is normally measured by a weighted sum of outputs to a weighted sum of inputs with relative efficiency of DEA being normally decided by either maximizing outputs or minimizing inputs. DMUs whose efficiency has a value of 1 provide satisfactory candidates based upon which a decision for choices can be made.

The healthcare service provision also requires contributions from qualitative measurements in decision-making. AHP, therefore, is capable of enhancing this capability. AHP can be used to: 1) establish priorities or the relative importance among the attributes using experts' opinions, using exhaustive paired comparison analysis whose consistency of deriving priorities is checked by $C R=C I / R I[31]$; 2) employ an algorithm of weighting for each of the attributes; 3) perform similar analysis for the alternative solution strategies for each of the attributes; 4) derive a single overall score for each of the alternative solution strategies; and 5) decide on an optimal solution 
according to the alternative solution strategies on their final score and choose the best $[10,32]$. As a multi-criteria decision-making (MCDM) methodology, AHP can therefore assist to rank the outputs of DEA, which comprise multiple DMUs that are efficient [33]. DEA and AHP, as an integrated approach, can support objectively and subjectively decision-making, in particular, on those complex decisions [34, 35].

\section{METHODS}

\subsection{The Healthcare Service Provision Model}

The ontology model in Figure 1 comprises the concepts of a healthcare domain. These concepts represent various agents and their affordance, i.e., healthcare providers, healthcare services and healthcare service provision. The concepts of society and nation establish a context for the organisation. As reflected in this model, the organisation can have several specifics, such as medical healthcare, quality commission, and ministerial department. The medical healthcare organisation must be registered with the quality commission to carry out medical practices. The quality commission assures that the service provider implemented the healthcare service policies, which is made by the ministerial department. Healthcare service policies are in turn shared across specific organisations. This group of concepts, with their ontological dependencies, describe a healthcare service provider. In the model, the medical healthcare is further defined by a role, i.e., either primary care (general practices) or secondary care (hospitals). In the context of referral, the information about the hospital is extensively used in the decision-making process. Medical healthcare organisations potentially play the role as a secondary (care) provider, or as a consultant, which can be further described by their determiners in \#description and \#profile (i.e., a provider's profile).

The healthcare service provider delivers its healthcare services; however, these services must be authorised and audited by the organisation. These services are

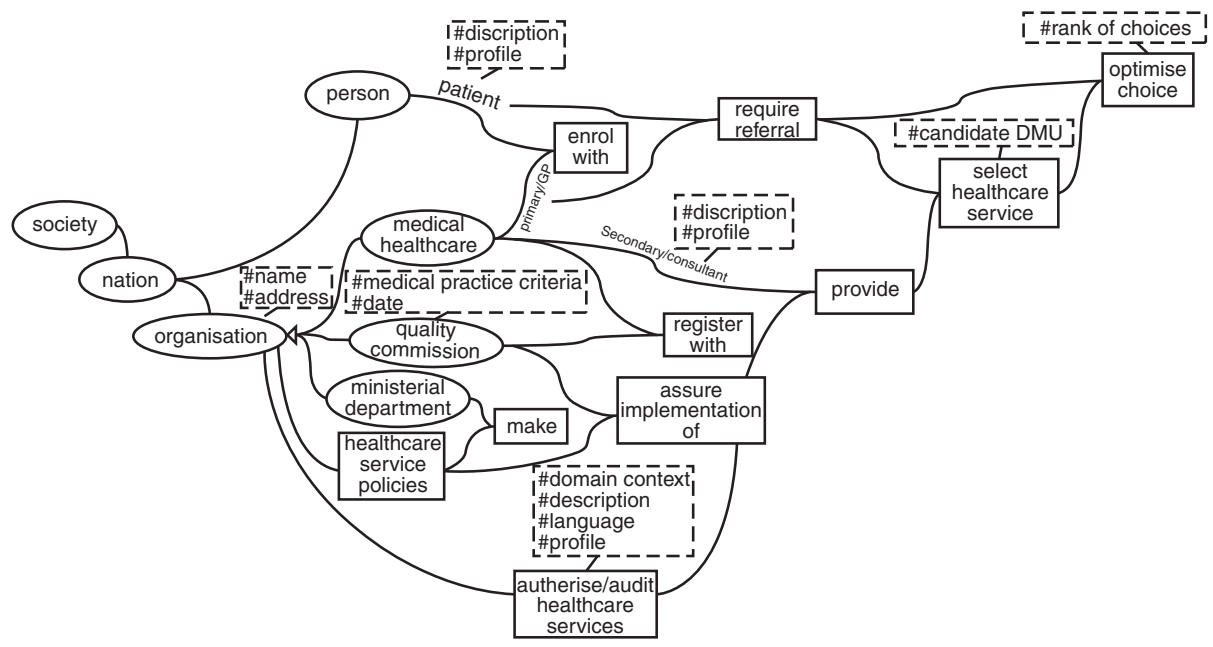

Figure 1. The ontology model of healthcare service provision. 
structured in \#profile (healthcare service profile) as the determiner of the authorise/audit healthcare services. A key stakeholder in this study is patient. A patient, as a person, is socially defined in the context of society and nation. The patient is further detailed with its determiners, i.e., \#description and \#profile (an individual patient's profile), which defines the properties of the patient. A patient is enrolled with a primary care from which he or she receives healthcare service.

In order to facilitate the referral service provision, three key processes are enabled in this model. These processes are described through the concepts require_referral, select_healthcare_service and optimise_choice. The require_referral process performs the functions to formulate a referral case according to the patient's referral request, and then captures the referral case in the patient profile. The formulation of the referral case is enabled by using CBR. The select_healthcare_service process uses the referral requirements, as specified in the referral case, to discover the closest matching healthcare service provider (i.e., hospital). The process carries out the DEA functions to benchmark the quality of service providers by using both profiles for provider and healthcare service. As a result, the selected service provider is presented as a DMU. In a case where there is more than one DMU satisfying the referral case, the optimise_choice process is carried out. In this optimise_choice process, multiple inputs, from both patient and GP, are taken into consideration by using APH. Consolidated referral choices are ranked in the optimise_choice process, which differentiates amongst selected DMUs. By the end of these processes, the optimal referral option is finally decided by considering both the patient and GP requirements.

\subsection{The Domain Knowledge Representation}

In the ontology model, there are three profiles: Patient Profile, Provider Profile, and Healthcare Services. The Patient Profile captures the personalised information, which includes patient_record in the Electronic Patient Record (EPR); the referral_case as a referral request, which is detailed by personalised_features; referral_decision; date_of_decision; and feedback (Figure 2). The personalised features represent a set of referral requirements (i.e., a tuple of preferences with the corresponding weights), which are perceived by a patient as important in relation to the specific health situation. This profile is used to discover matching provider's offerings.

The concept of medical_healthcare, especially considering the role of consultant in the healthcare service provision, is defined by the Provider Profile, as shown in Figure 3. This profile specifies provider characteristics and their competence with both qualitative and quantitative features. The general information concerning the service provider is structured as including provider_ID; name; geo_location; unit; and hospital_sector to which the provider belongs. The support_service represents the providers' non-medical competences, which align to patients' preferences when they request healthcare services. In context of the quality_assessment, a hospital's performance is defined by the quality_commission as "excellent", "very good", "good", "average", "satisfactory", or "poor", which are rated from 5 down to 1 . A patient therefore may refer to the quality_assessment together with the support_service when searching healthcare services in order to satisfy personalised preferences. The patient_feedback reveals the 


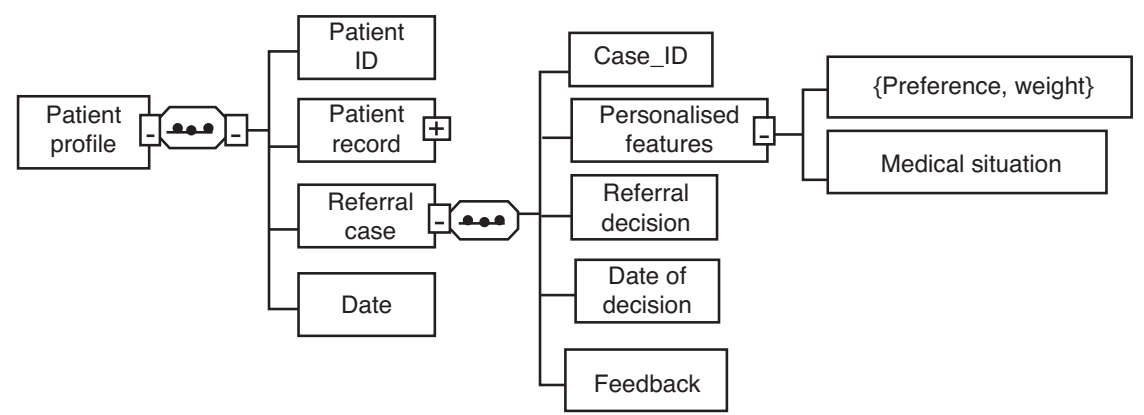

Figure 2. The patient profile.

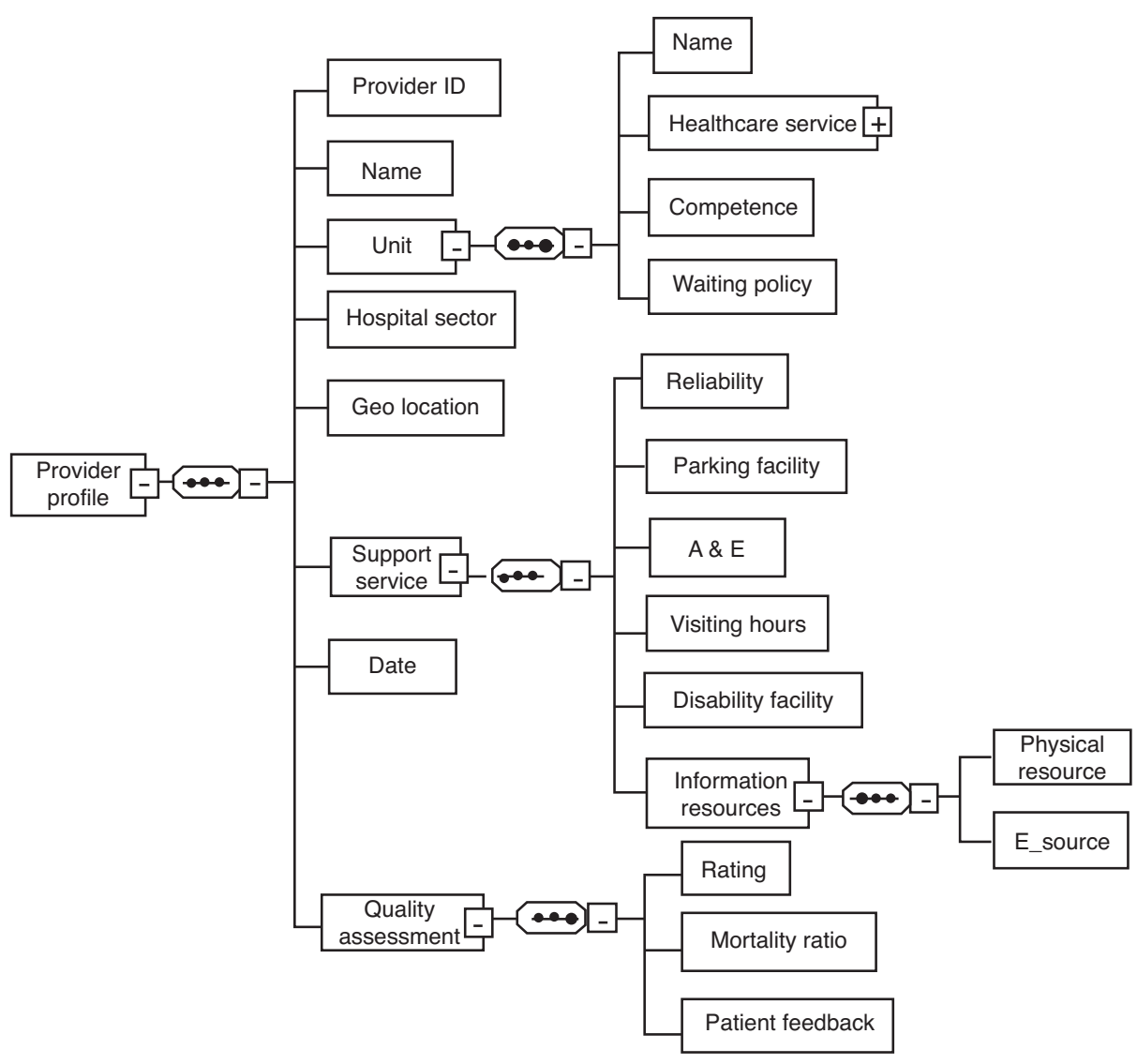

Figure 3. The healthcare service provider profile. 


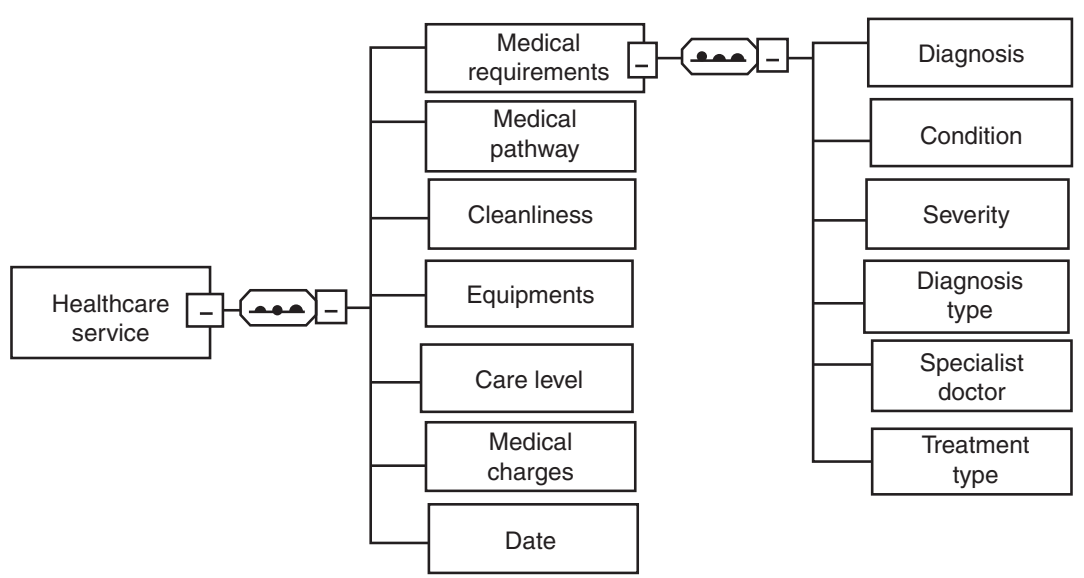

Figure 4. The healthcare service profile.

patient's justification concerning the hospital's performance for a specific need. The unit is further featured by a list, which defines unit name; care level; cleanliness; duration as a waiting policy for treatment expressed in days, e.g., immediately= "1", urgently= "14", soon= "60", and routinely= "90" [36]; and a specific portfolio of healthcare_service, which is provided by the corresponding unit.

The healthcare_service is detailed by the healthcare_service profile (Figure 4). The medical_requirements defines the diagnosis for which the patient is referred. The health_condition specifies the medical condition of the patient as being either acute or non-acute. A severity of the patient's health diagnosis is expressed by the $G P$ as being mild, moderate, or severe. These medical requirements can be used to support a medical_pathway, which is carried out by the specialist doctor when the patient is treated. The diagnosis_type, specialist_doctor, and treatment_type can be updated, as required, in relation to the specific treatment context. Other healthcare_service requirements, such as cleanliness measures, equipment required for treatment, type of care for medical practice, and service provision charge policy, can be added as required. The unit embodies, in part, the provider's medical competence in a particular healthcare_service.

The information captured in the Provider Profile can therefore assist in the formulation of a set of focal DMUs which determine suitable healthcare services based on a details of the referral request. Both the patient's profile and the provider's profile define the service characteristics and their provision requirements which are verified by the healthcare service criteria in Table 1.

\subsection{Analytical Processing for Service Discovery}

A referral decision is made through three analytical processes. The first process is the require_referral process, which is processed when a new referral requirement is received according to the specified medical_situation. Such a referral request is 
transformed into a set of personalised problem features, with their corresponding weights, which form the criteria for selecting service providers. In this process, the following workflow is executed to create the referral case.

$<$ workflow: require_referral>

$<$ whenever> a new referral is requested by patient jointly with the GP AND patient preferences are specified using a pair-wise comparison analysis as in Appendix A </whenever $>$

$<$ if $>$ there is no referral case exists in Patient Profile $<$ if $>$

$<$ then $>$ case-based creator $</$ then $>$

$<$ is $>$ obliged $<$ is $>$

$<$ to $>$ store the $C^{\text {new }}$ in Patient Profile $</$ to $>$

$<$ if $>$ there are existing referral cases in Patient Profile $</$ if $>$

$<$ then $>$ case-based analyser $</$ then $>$

$<$ is $>$ obliged $</$ is $>$

$<$ to $>$ create $C^{\text {new }} \subset\{$ diagnosis, personalised feature, weight, pf value $\}$ AND find a matched case by

$$
\operatorname{Simil}\left(C^{\text {new }}, C^{\text {retrieved }}\right)=\frac{\sum_{i}^{m} w_{i} \times \operatorname{sim}\left(f_{i}^{\text {new }}, f_{i}^{\text {retrieved }}\right)}{\sum_{i}^{m} w_{i}} \times 100 \%
$$

$</$ to $>$

$<$ if $>$ the $\operatorname{Simil}\left(C^{\text {new }}, C^{\text {retrieved }}\right)>=80 \%</$ if $>$

$<$ then $>$ case-based analyser $</$ then $>$

$<$ is $>$ obliged $<$ is $>$

$<$ to $>$ adopt the matched referral case if the $C^{\text {retrieved }}$ found OR the patient and GP jointly select one

from the list of matching referral cases if more than one is found $</$ to $>$

$<$ if $>$ there is the $\operatorname{Simil}\left(C^{\text {new }}, C^{\text {retrieved }}\right)<80 \%<$ if $>$

$<$ then $>$ case-based analyser $</$ then $>$

$<$ is $>$ obliged $<$ is $>$

$<$ to $>$ flag "no match" and store the $C^{\text {new }}$ in the Patient Profile $</$ to $>$

$<$ /workflow: require_referral>

The second process is the select_healthcare_service, where the $C^{\text {new }}$ is used to derive variables for discovering a suitable hospital. The process takes the multi-input and multi-output quantitative variables to measure hospitals' performance and select the DMUs whose maximum efficiencies $\left(E_{0}\right)=1$.

$<$ workflow: select_healthcare_service $>$

$<$ whenever $>$ a referral decision is required $</$ whenever $>$

$<$ if $>$ a $C^{\text {new }}$ is retrieved AND the authorised healthcare services exist $<$ /if $>$

$<$ then $>$ select engine $</$ then $>$

$<$ is $>$ obliged $</$ is $>$

$<$ to $>$ extract $\{$ multi-input, multi-output $\}$ from the $C^{\text {new }}$ AND select the DMUs whose $E_{0}=1$ by 


$$
\begin{aligned}
\operatorname{Max} E_{0}= & \frac{\sum_{r} u_{r} y_{r j o}}{\sum_{i} v_{i} x_{i j o}}=1 \quad \text { AND } \\
& \sum_{i} u_{r} y_{i j}-\sum_{i} v_{i} x_{i j} \leq 0, \text { where } j=1,2, \ldots, n, \text { and }</ \text { to }>
\end{aligned}
$$

$<$ if $>$ All DMUs whose $E_{0} \pi 1</$ if $>$

$<$ then $>$ select engine $</$ then $>$

$<$ is $>$ obliged $</$ is $>$

$<$ to $>$ suggest the patient for a revision of $\{$ multi-input, multi-output $\}$ AND select the DMUs whose $E_{0}=1</$ to $>$

$<$ if $>$ exactly one DMU satisfies the patient and GP requirement $</$ if $>$

$<$ then $>$ select engine $</$ then $>$

$<$ is $>$ obliged $<$ is $>$

$<$ to $>$ accept the DMU for its representing hospital AND update the referral_case in Patient Profile

$</$ to $>$

$<$ if $>$ more than one DMUs satisfy the patient and GP requirement $</$ if $>$

$<$ then $>$ select engine $</$ then $>$

$<$ is $>$ obliged $<$ is $>$

$<$ to $>$ (allow the patient to take the GP's recommendation AND update the referral_case in Patient Profile) OR (enter the optimise_choice process to further analyse these DMUs) $</$ to $>$

$</$ workflow: select_healthcare_service $>$

The third process is the optimise_choice, which aims to benchmark the service provider's performance. If multiple qualified hospitals are selected, the patient and GP make a choice from service providers where $E_{0}=1$. There are different scenarios generated from this process. One scenario is that none of the DMUs can be selected. The patient is then notified to revise the \{personalised feature, weight requirement; however, this revision behaviour has to be sensibly controlled to avoid the patient being inappropriately advised. Revised requirements are re-entered into the selection process until a hospital is found. It is possible that more than one DMU may be selected, which imposes some difficulties in making the desired choice. The capability of the given selection process, however, does not enable evaluation of such complex problems. To handle this scenario, the optimise_choice process is carried out.

<workflow: optimise_choice>

$<$ whenever $>$ the candidate DMUs with $E_{0}=1$ need ranking over their final score and choose the best

$</$ whenever $>$

$<$ if $>$ the set of $\{$ alternative DMUs, criteria\} is structured with the corresponding weights derived by using Appendix A $<$ if $>$

$<$ then $>$ optimise engine $</$ then $>$

$<$ is $>$ obliged $</$ is $>$ 
$<$ to $>$ perform the comparison analysis of the DMUs with each corresponding criterion to compute their final score for ranking $</$ to $>$

$<$ if $>$ the winning DMU satisfies the patient and GP requirement $</$ if $>$

$<$ then $>$ optimise engine $</$ then $>$

$<$ is $>$ obliged $<$ is $>$

$<$ to $>$ accept the winning DMU for its representing hospital AND update the referral_case in Patient Profile $</$ to $>$

$</$ workflow: optimise_choice $>$

When these three processes are completed, the GP and patient have the opportunity to review the intermediate results and make any required alterations to the criteria and weightings until a satisfactory outcome is produced. By facilitating an iterative capability, the method can assist patients when making sensible decisions. However, a final referral decision ultimately requires human stakeholder judgement.

\section{RESULTS}

A trial case was tested to validate the proposed ontology model. The trial involved sixty-four patients and four GPs to form a sample population to represent typical referral cases of non-acute health conditions with different degrees of severity. These GPs are family physicians, with broad competencies across a range of medical and surgical conditions, looking after patients in the primary care setting. The referral requests were analysed using our ontology model, which aimed to facilitate the understanding of the influential factors in the referral practice [37]. The referral processes were then executed and the referral choices were made by the patient and GP. Amongst these referral requests, a representative referral case is given here in full detail to demonstrate how patients and GPs decided upon referrals through the require_referral, select_healthcare_service, and optimise_choice analytical processes.

Base on the use of Patient Profile, the referral request with case ID REF14.07 in Figure 5 was produced based on the medical situation of "abnormal skin growth" and specified as a non-acute condition. This patient and the GP articulated personal referral requirements which consisted of NHS hospital or independent hospital; patient_feedback equal or greater than 7 out of 10; a waiting time "duration" less than 14 days; and "moderate" severity for "abnormal skin growth". The other three preferences, i.e., the cleanliness measure of hospital, level of care, and the reliability in terms of quality of treatment service, were considered as important factors, and priorities were specified by the patient although no specific values were assigned. The prioritisation process deployed a fundamental scale for feature weightings in the referral case. This activity was important for the require_referral workflow where the matching process takes place.

The formulation of the referral case led to the select_healthcare_service workflow for the selection of healthcare service providers. This process benchmarked the provider's performance, such as the unit and support_service in the Provider Profile, and the medical capability, i.e., healthcare_service in the Healthcare Service Profile. This analysis took $x_{r j}$ and $y_{r j}$ with the weight $\left(u_{r}, v_{r}\right)=1$ (Table 2), which is derived from 


\begin{tabular}{|c|c|c|}
\hline $\begin{array}{l}\text { Case: } C^{B S} \\
\text { diagnosis: } \\
\text { condition: } \\
\text { specialist_doctor: } \\
\text { severity: }\end{array}$ & \multicolumn{2}{|c|}{$\begin{array}{l}\text { ID: REF14.07 } \\
\text { abnormal skin growth } \\
\text { non-acute } \\
\text { dermatologist } \\
\text { moderate }\end{array}$} \\
\hline personalised features ( & weight $(w)$ & pf value \\
\hline hospital_sector & 0.0263 & NHS hospital/Indipendent \\
\hline cleanliness & 0.2148 & - \\
\hline care level & 0.3947 & - \\
\hline relaibility & 0.3905 & - \\
\hline patient_feedback & 0.1956 & 7 \\
\hline duration & 0.1384 & 14 \\
\hline distance & 0.0403 & 10 \\
\hline referral decision: & date of decisi & \\
\hline
\end{tabular}

Figure 5. REF14.07 referral case.

Table 2. The selection results for REF14.07

\begin{tabular}{|c|c|c|c|c|c|c|c|c|}
\hline \multirow{2}{*}{$\begin{array}{l}\text { Case_ID: } \\
\text { REF14.07 } \\
\text { DMU }\end{array}$} & \multicolumn{2}{|c|}{ Input } & \multicolumn{2}{|c|}{ Output } & \multicolumn{4}{|c|}{ Efficiency Computation } \\
\hline & $\begin{array}{l}\text { waiting } \\
\text { time }\end{array}$ & distance & $\begin{array}{l}\text { specialist } \\
\text { doctor }\end{array}$ & $\begin{array}{c}\text { patient } \\
\text { feedback }\end{array}$ & $\begin{array}{c}\text { weighted } \\
\text { Output }\end{array}$ & $\begin{array}{l}\text { weighted } \\
\text { Input }\end{array}$ & $\begin{array}{c}\text { efficiency } \\
(E)\end{array}$ & Working \\
\hline & $x_{1}$ & $x_{2}$ & $y_{1}$ & $y_{2}$ & $\Sigma u_{r} y_{r j}$ & $\Sigma v_{r} x_{r j}$ & $\Sigma u_{r} y_{r j} / \Sigma v_{r} x_{r j}$ & $\sum_{r} u_{r} y_{r j}-\sum_{i} v_{i} x_{i j} \leq 0$ \\
\hline HCONH-450 & 14.0000 & 1.5000 & 1.0000 & 7.0000 & 1.0000 & 1.0000 & 1.0000 & 0.0000 \\
\hline HCONH-266 & 21.0000 & 2.6000 & 1.0000 & 8.0000 & 0.7304 & 1.0000 & 0.7304 & -0.2696 \\
\hline HCOIN-255 & 7.0000 & 5.0000 & 2.0000 & 8.5000 & 1.0000 & 1.0000 & 1.0000 & 0.0000 \\
\hline HCOIN-540 & 14.0000 & 7.3000 & 1.0000 & 7.2000 & 0.5209 & 1.0000 & 0.5209 & -0.4791 \\
\hline HCONH-663 & 28.0000 & 10.0000 & 1.0000 & 7.5000 & 0.3373 & 1.0000 & 0.3373 & -0.6627 \\
\hline HCONH-335 & 21.0000 & 12.5000 & 2.0000 & 8.0000 & 0.3908 & 1.0000 & 0.3908 & -0.6092 \\
\hline
\end{tabular}

the personalised features defined in REF14.07. The input and output variables were determined by the priority of distance and waiting_time being minimised based on the NHS policy, and specialist_doctor and patient_feedback is maximised in the efficiency computation. As a result, 6 DMUs were discovered. Each DMU represents a healthcare service provider (i.e., a hospital). HCONH signifies an NHS hospital, whilst HCOIN indicates an independent hospital, with HCO standing for "healthcare organisation". 


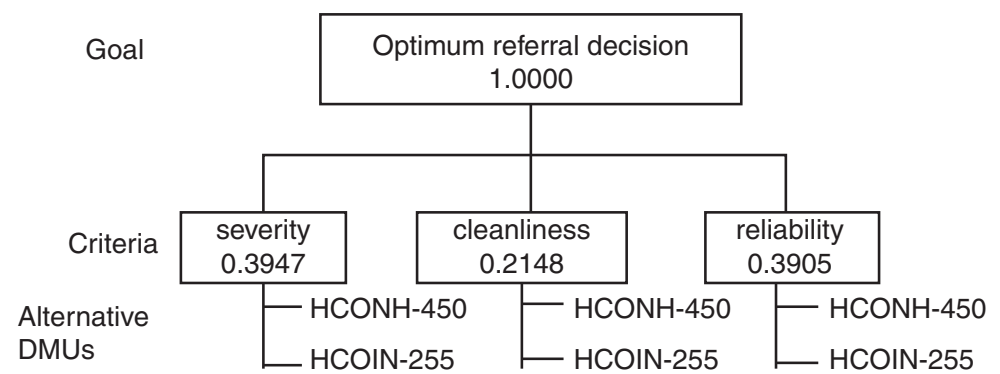

Figure 6. Decision on the optimum referral choice.

Table 3. The DMUs ranking for REF14.07

\begin{tabular}{lcccc}
\hline Referral case: REF14.07 & \multicolumn{3}{c}{} \\
\hline Attribute & Care level & Cleanliness & Reliability & $\begin{array}{c}\text { Alternative priority } \\
\text { weight }\end{array}$ \\
\hline Priority weight & 0.3947 & 0.2148 & 0.3905 & \\
HCONH-450 & 0.7500 & 0.2500 & 0.1250 & 0.3985 \\
HCOIN-255 & 0.2500 & 0.7500 & 0.8750 & 0.6015 \\
\hline
\end{tabular}

Out of 6 hospitals, only 2 DMUs had a maximum efficiency $E_{0}=1$, which were HCONH-450 and HCOIN-255, implying that the other 4 DMUs are dissatisfactory. To decide upon a provider, the optimise _ choice process was carried out to provide a ranking between these two candidate DMUs.

Figure 6 diagrammatically structures the optimise_choise process with \{goal, alternatives, criteria\}, with \{care_level, cleanliness, reliability\} used as the criteria differentiating the two hospitals within the solution analysis. The result of the comparison process showed a consistency ratio of $1.04 \%$ which is satisfactory.

The alternative priority weights are calculated to establish the ranking of the two hospitals when considering the specific attributes. Table 3 presents the alternative priority weights of HCONH-450 with $39.85 \%$ and HCOIN-255 with $60.15 \%$. Therefore, HCOIN-255 was considered the best choice for the REF14.07 referral case (Figure 7).

\section{DISCUSSION}

The referral of medical services in the UK can be automated to improve the efficiency, specialisation, and quality of healthcare provision, as demonstrated in this case study. The proposed automation was validated in this paper, via a user trial. Appendix B presents the 3-dimensional measures used to capture patients and GPs' feedback concerning the analytical process and results. A review followed a qualitative trial on 64 patients and 4 GPs/experts to assess the validity and added value of our approach. The instrument, as shown in Appendix B, was used to obtain the users' judgment. The 


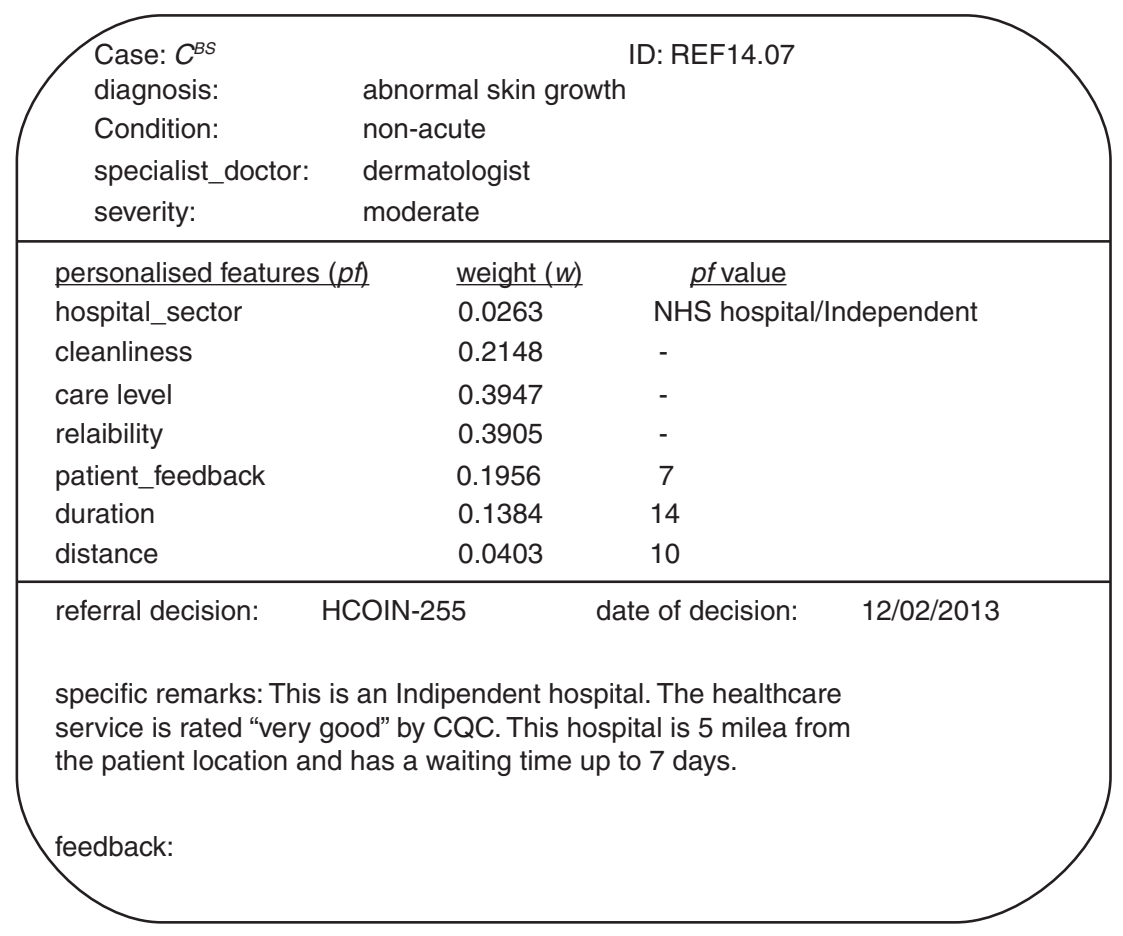

Figure 7. The optimum referral decision for REF14.07.

assessment focused on usability, cost-effectiveness and involvement throughout the decision process. Usability assessed the ease of use of the approach, i.e., ease of finding information, flexibility of expressing preferences, clarity of what user has to do, and acceptability of the referral result/outcome. Cost-effectiveness considered the time required to reach an acceptable result, and the overall user experience with our approach, which offers more user involvement and hence better perception of value for money in the referral decisions. Involvement in the decision process measured whether users felt they had control and freedom in the decision process, and how the approach facilitates independence and promotes privacy in the referral decision process.

Figure 8 presents the results from the healthcare provision heuristics. The overall usability result (Figure 8a) showed that $37 \%$ of stakeholders indicated being very satisfied, $14 \%$ highly satisfied, and $33 \%$ are satisfied. The result shows that the majority $(84 \%)$ found our approach to be usable. Cost-effectiveness results (Figure $8 \mathrm{~b}$ ) show that the majority of users $(82 \%)$ indicated a positive experience (i.e., being satisfied, very satisfied, and highly satisfied). This result is significant as it indicates that users were satisfied with the time it took to reach the final referral decision. The proposed model suggests that increased user involvement, in the future, can be achieved resulting in timely referral decisions. Figure $8 \mathrm{c}$ illustrates user feedback on their involvement throughout the referral decision process. Forty-five percent (45\%) of the users indicated 


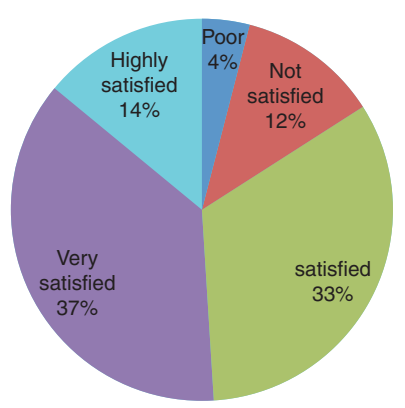

Figure 8.

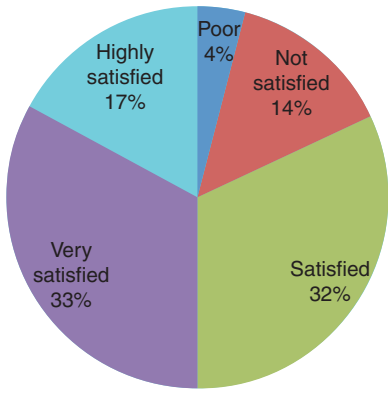

(b) Cost-effectiveness

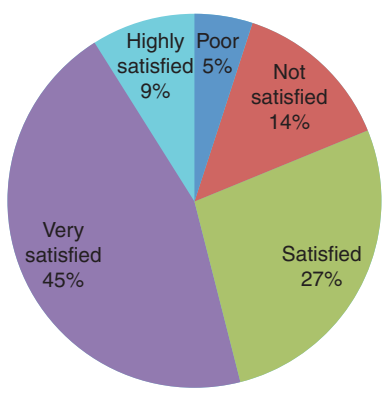

(c) User involvement in referral decision

that they were very satisfied, and $9 \%$ were highly satisfied. This result indicates that users saw our approach as providing a high level of control and freedom in the referral decision process, arguably resulting in user confidence and engagement in the care selection process.

This study adopts a qualitative research approach. There is no common agreement of a standard data sample size; therefore as usual, the data size in this qualitative research was driven by the research goal $[37,38,39]$. The goal of our research is to analyse user experiences and perceptions. We have obtained the sample size of 68 including General Practitioners (GP's) and non-acute referral patients to determine the user expectations (vs. requests) and experiences (vs. perceptions) in our research work. Their feedback assisted us to analyse the credibility of our method in supporting the participants involved in our study.

There were a number of limitations of our work. Firstly, the given referral process could only be viably tested with non-acute referrals. Although technically, our approach is also suitable for acute cases, we were unable to capture the data and test with acute referral cases. Secondly, our model should explicitly integrate the referral process to allow GPs to veto recommendations from patients on referral selection. Patients may have a favourite hospital or preferred consultant, but the GP may have professional grounds and justifications to be empowered not to allow patient's input through the selection process. Thirdly, it is recognised that the lack of information about hospital performance at their diagnosis services/units level imposes restrictions on the actualisation of the patient-centred healthcare service provision. This is especially true in cases where a patient is more concerned about the performance of a specific care unit than that of the overall hospital. Fourthly, the data size and structure is a challenging issue. Although the current repository works with structured data, we have discovered that certain forms of unstructured data from disparate data sources, e.g., non-digitised records, and social media (e.g., Facebook, Twitter, and personal blogs) are useful to capturing patients' feedback. A big data approach [40] can be employed to enhance the analysis of healthcare service and decision making in the future. Finally, we plan to extend the technical capabilities of the ontology model by employing data visualisation approaches [41]. By doing this we aim to enhance users' participation while they deal 
with the complexity of personalisation and analytical process involved in decision making. As our work is based on the theory of norms, we believe that the quality of decision on referrals can be maintained.

\section{CONCLUSION}

We have identified the lack of patient participation, especially in making hospital referrals, in the current healthcare service provision. This paper presents a method which conforms to key NHS policy requirements for patient involvement in healthcare decision making. This new method was developed specifically to facilitate the key referral processes: require_referral, select_healthcare_service, and optimise_choice.

The overall results of our research show that it is feasible to involve patients in the referral process; however, there is a challenge in capturing and representing patient's and healthcare provider's requirements. Our knowledge representation approach utilises domain conceptualisation to extend the capability of personalisation for decision support. The ontology approach and profiling technology enabled modelling of the requirements and workflow of the referral process. To ensure professionalism and reliability for the service provision, the method can explicitly be embedded in service quality standards issued by, e.g., SERVQUAL, CQC and the NHS, as norms. The norms, as business rules, can be used to govern the service provision process. Through the hybrid analytical approach including CBR, DEA and AHP, this paper has shown that insights can be acquired to support multiple stakeholders in the discovery of useful and appropriate information, which will ultimately support healthcare decision making.

\section{ACKNOWLEDGEMENTS}

This project is supported in part by the Faculty of Economics and Administration of the King Abdulaziz University. The authors would like to thank Dr Stephen Gulliver for his valuable comments and input to this paper. Special thanks also go to the anonymous reviewers for their thorough, critical and constructive comments which helped tremendously in the improvement of our work.

\section{CONFLICT OF INTERESTS}

The authors declare that there is no conflict of interest.

\section{REFERENCES}

[1] NHS. 2013/14 Choice Framework. Department of Health, www.dh.gov.uk/publications, accessed 15 September 2013

[2] Cenfetelli RT, Benbasat I, Al-Natour S. Addressing the what and how of online services: positioning supporting-services functionality and service quality for business-to-consumer success. Information Systems Research, 2008, 19(2):161-181.

[3] Landrum H, Prybutok VR, Zhang X, Peak D. Measuring IS systems service quality with SERVQUAL: users' perceptions of relative importance of the five SERVPERF dimensions. Informing science: the international journal of an emerging trans-discipline, 2009, 12:17-35.

[4] Parasuraman A, Zeithaml VA, Berry LL. SERVQUAL: A multiple-item scale for measuring customer perceptions of service quality. Journal of Retailing, 1998, 64(1):12-40.

[5] CQC. Raising standards, putting people first - our strategy for 2013 to 2016. Care Quality Commission, UK, w.cqc.org.uk/sites/default/files/media/documents/20130503_cqc_strategy_2013_ final_cm_tagged.pdf, accessed 01 October 2013. 
[6] Jøsang A, Ismail R, Colin B. A survey of trust and reputation systems for online service provision. Decision Support Systems, 2007, 43(2):618-644.

[7] Kim DJ, Ferrin DL, Rao HR. Trust and satisfaction, two stepping stones for successful e-commerce relationships: a longitudinal exploration. Information Systems Research, 2009, 20(2):237-257.

[8] Mantzana V, Themistocleous M, Irani Z, Morabito V. Identifying healthcare actors involved in the adoption of information systems. European Journal of Information Systems, 2007, 16(1):91-102.

[9] Boonstra A, Boddy D, Bell S. Stakeholder management in IOS projects: analysis of an attempt to implement an electronic patient file. European Journal of Information Systems, 2008, 17(2):100-111.

[10] Büyüközkan G, Çifçi G, Güleryüz S. Strategic analysis of healthcare service quality using fuzzy AHP methodology. Expert Systems with Applications, 2011, 38:9407-9424.

[11] Scheepers R, Scheepers H, Ngwenyama OK. Contextual influences on user satisfaction with mobile computing: findings from two healthcare organisations. European Journal of Information Systems, 2006, 15(3):261-268.

[12] Liu K, Sun L, Fu Y. Ontological modelling of content management and provision. Journal of Information and Software Technology Elsevier, 2008, 50(11):1155-1164.

[13] Sun L, Mushi CJ. Case-based analysis in user requirements modelling for knowledge construction. Information and Software Technology, 2010, 52(7):770-777.

[14] Soffer P, Hadar I. Applying ontology-based rules to conceptual modelling: a reflection on modelling decision-making. European Journal of Information Systems, 2007, 16(5):599-611.

[15] Liu K. Semiotics in information systems engineering. Cambridge University Press, Cambridge, 2000.

[16] Mika P. Ontologies are us: a unified model of social networks and semantics. Journal of web semantics, 2007. 5(1):5-15.

[17] Fensel D, Ontologies: silver bullet for knowledge management and electronic commerce. SpringerVerlag, Berlin, 2001.

[18] Stamper RK, Hafkamp M, Ades Y. Understanding the roles of signs and norms in organisations - a semiotic approach to information systems design and behaviour, Information Technology, Elsevier, 2000, 19(1):67-116.

[19] Sun L, Ousmanou K, Cross M. An ontological modelling of user requirements for personalised information provision. Information Systems Frontier, 2010, 12(3):337-356.

[20] Gibson JJ. The Ecological Approach to Visual Perception. Boston: Houghton Mifflin Company, 1968.

[21] IEEE. P1484.2/D8 Draft standard for learning technology - public and private information (PAPI) for learners (PAPI Learner) - Core Features. IEEE Computer Society, Institute of Electrical and Electronics Engineers, Inc., 2001.

[22] IMS. IMS Learner information package (LIP) specification, IMS Global learning consortium, Inc. www.imsproject.org/profiles/, accessed 04 October 2013.

[23] Fenza G, Furno D, Loia V. Hybrid approach for context-ware service discovery in healthcare domain. Journal of Computer and System Sciences, Elsevier, 2012, 78:1232-1247.

[24] Holt A, Bichindaritz I, Schmidt R. Medical applications in case-based reasoning. The Knowledge Engineering Review, 2005, 20(3):289-292.

[25] Niemeijer GC, Does RJ, Mast J, Trip A, Heuvel J. Generic project definitions for improvement of health care delivery: a case-based approach. Quality Management in Health Care, 2011, 20(2):152-164.

[26] Saaty TL. Relative measurement and its generalization in decision making: why pairwise comparisons are central in mathematics for the measurement of intangible factors - the analytic hierarchy/network process, Review of the Royal Spanish Academy of Sciences, Series A, Mathematics, 2008, 102(2):251-318.

[27] Kuntz L, Vera A. Modular organization and hospital performance. Health Services Management Research, 2007, 20(1):48-58. 
[28] Pecchia L, Bracale U, Melillo P, Sansone M, Bracale M. AHP for health technology assessment. In Proceedings of the International Symposium on the Analytic Hierarchy Process, University of Pittsburgh, PA, 2009, pp. 1-8.

[29] Charnes A, Cooper W, Lewis AY, Seiford LM. Data envelopment analysis: theory, methodology and application. Kluwer Academic Publishers, MA, 1997.

[30] Juan Y. A hybrid approach using data envelopment analysis and case-based reasoning for housing refurbishment contractors' selection and performance improvement. Expert Systems with Applications, 2009, 36(3):5702-5710.

[31] Ishizaka A, Labib A. Review of the main developments in the analytic hierarchy process. Expert Systems with Applications, 2011, 38(11):14336-14345.

[32] Dura'n O, Aguilo J. Computer-aided machine-tool selection based on a fuzzy-AHP approach. Expert Systems with Applications, 2008, 34:1787-1794.

[33] Ramanathan R. Data envelopment analysis for weight derivation and aggregation in the analytic hierarchy process. Computer \& Operations Research, 2006, 33:1289-1307.

[34] Chow CC, Luk P. A strategic service quality approach using analytic hierarchy process. Managing Service Quality, 2005, 15(3):78-289.

[35] Parameshwaran R, Srinivasan PSS, Punniyamoorthy M, Charunyanath ST, Ashwin C. Integrating fuzzy analytical hierarchy process and data envelopment analysis for performance management for automobile repair shops. European Journal of Industrial Engineering, 2009, 3(4):450-467.

[36] Baughan P, O'Neill B, Fletcher E. Auditing the diagnosis of cancer in primary care: the experience in Scotland. British Journal of Cancer, 2009, 101:87-91.

[37] O'Reilly M, Parker N. Unsatisfactory saturation': a critical exploration of the notion of saturated sample sizes in qualitative research, Qualitative Research, 2013, 13(2):190-197.

[38] Guest G, Bunce A, Johnson L. How many interviews are enough? An experiment with data saturation and variability, Field Methods, 2006, 18(1):59-82.

[39] Mason M. Sample Size and Saturation in PhD Studies Using Qualitative Interviews, Forum Qualitative Sozialforschung, Qualitative Social Research, 2010, 11(3).

[40] Zikopoulos PC, Eaton C, deRoos D, Deutsch T, Lapis G. Understanding big data: analytics for enterprise class Hadoop and streaming data. McGraw Hill, New York, 2012, ISBN: 9780071790536

[41] White C. Using big data for smarter decision making. IBM BI Research, All Rights Reserved, 2011. 


\section{APPENDIX A. THE PATIENT'S PRIORITIES SURVEY}

In order to aid patient participation in the referral process, the personal preferences can be expressed through the technique in Figure A.1. The result forms a weight associated with the corresponding preference feature in require_referral. These weights are also employed in the optimise_choice for ranking alternatives.

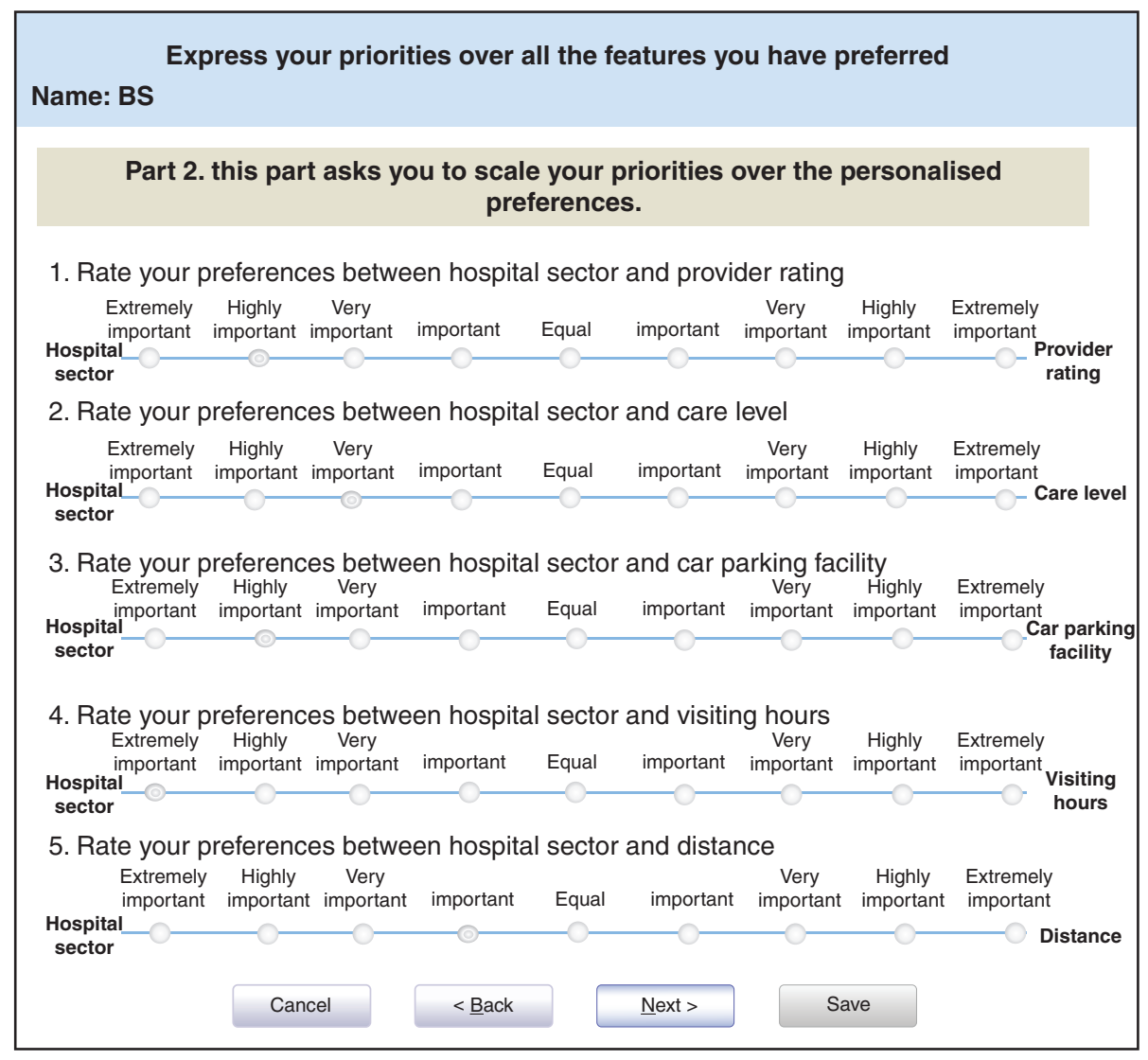

Figure A.1. The patient's survey technique.

\section{APPENDIX B. USERS' REVIEW INSTRUMENT}

The validation method consists of the measures presented in Table B.1. Each measure is rated as 1-poor, 2-not satisfied, 3-satisfied, 4-very satisfied, or 5-highly satisfied. 
Table B.1. The validation measures

\begin{tabular}{|c|c|c|c|c|c|c|}
\hline Dimension: usability & Code & 1 & 2 & 3 & 4 & 5 \\
\hline $\begin{array}{l}\text { (i) Ease of use (ease of finding information, flexibility } \\
\text { of expressing preferences, clarity of what to be done) }\end{array}$ & US01 & & & & & \\
\hline (ii) Referral result & US02 & & & & & \\
\hline Dimension: cost-effectiveness & Code & 1 & 2 & 3 & 4 & 5 \\
\hline $\begin{array}{l}\text { (i) Time to reach the acceptable referral decision } \\
\text { (ii) Overall experience with the proposed approach }\end{array}$ & $\begin{array}{l}\text { CE01 } \\
\text { CE02 }\end{array}$ & & & & & \\
\hline Dimension: user involvement in referral decision & Code & 1 & 2 & 3 & 4 & 5 \\
\hline $\begin{array}{l}\text { (i) Your control and freedom in the decision process } \\
\text { (ii) Facilitating independence in the referral decision } \\
\text { (iii) Promotes privacy }\end{array}$ & $\begin{array}{l}\text { IP01 } \\
\text { IP02 } \\
\text { IP03 }\end{array}$ & & & & & \\
\hline
\end{tabular}





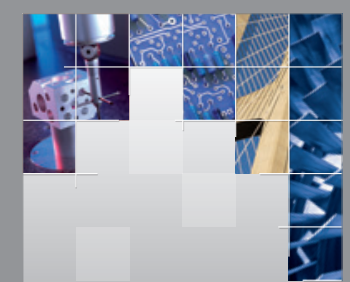

\section{Enfincering}
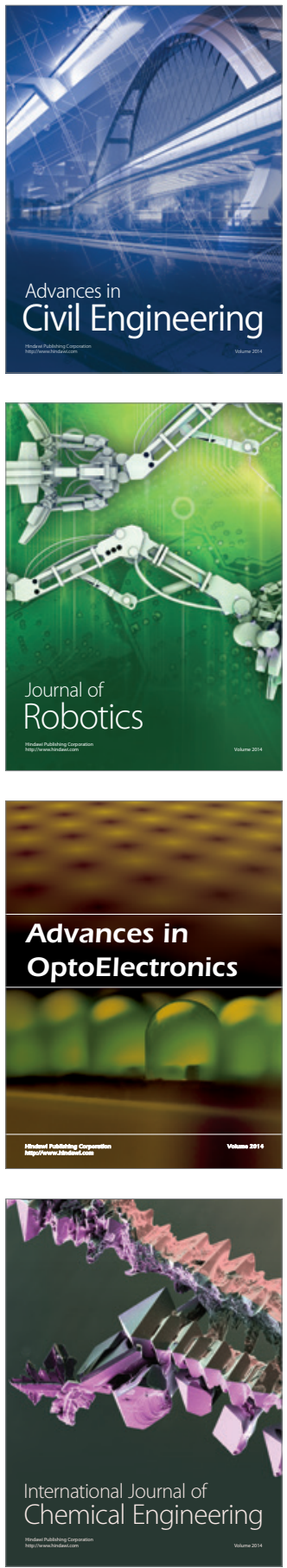

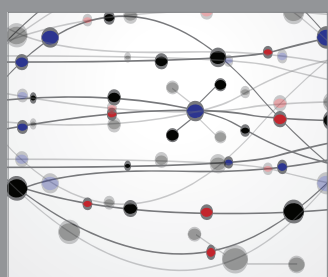

The Scientific World Journal

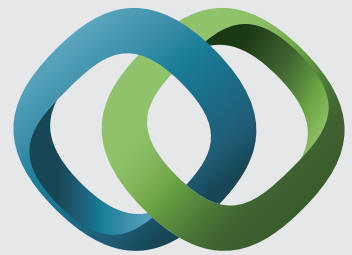

\section{Hindawi}

Submit your manuscripts at

http://www.hindawi.com
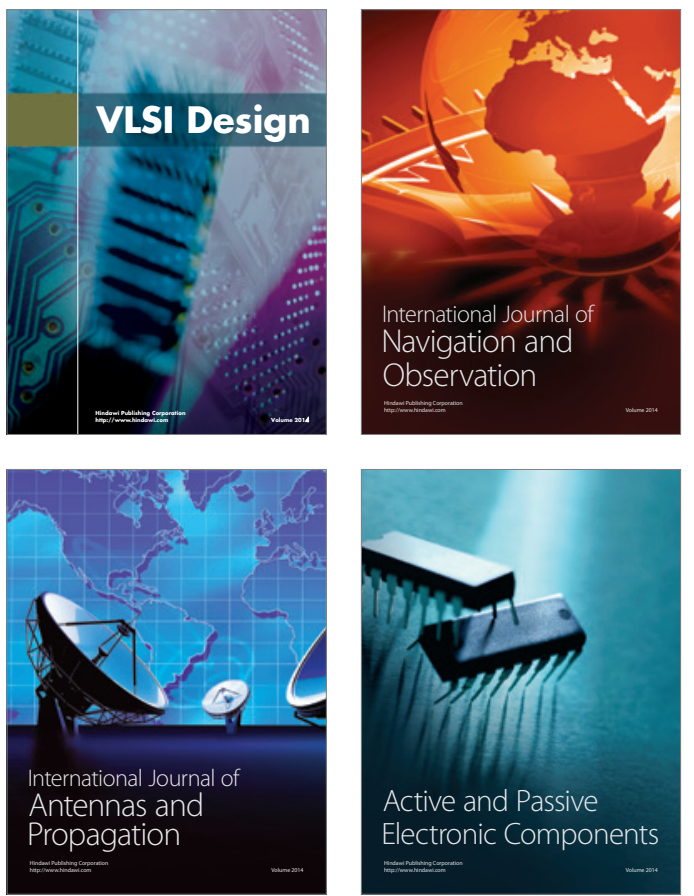
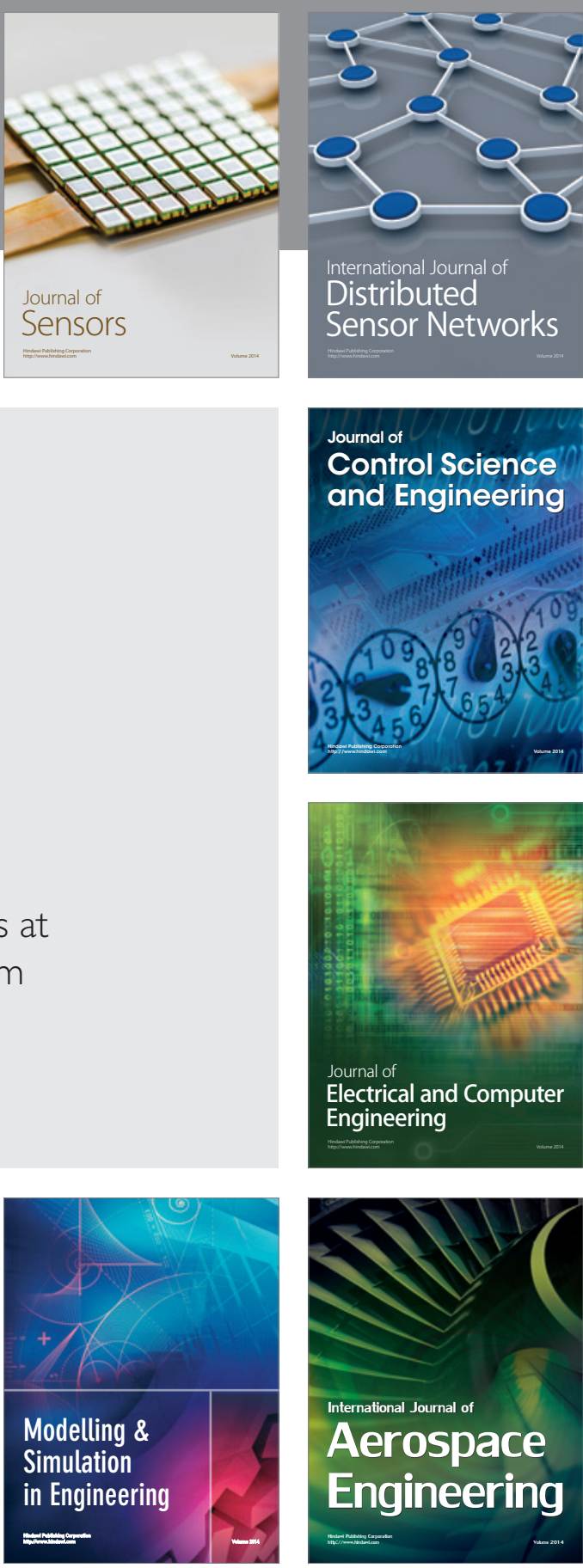

International Journal of

Distributed

Sensor Networks

Journal of

Control Science

and Engineering
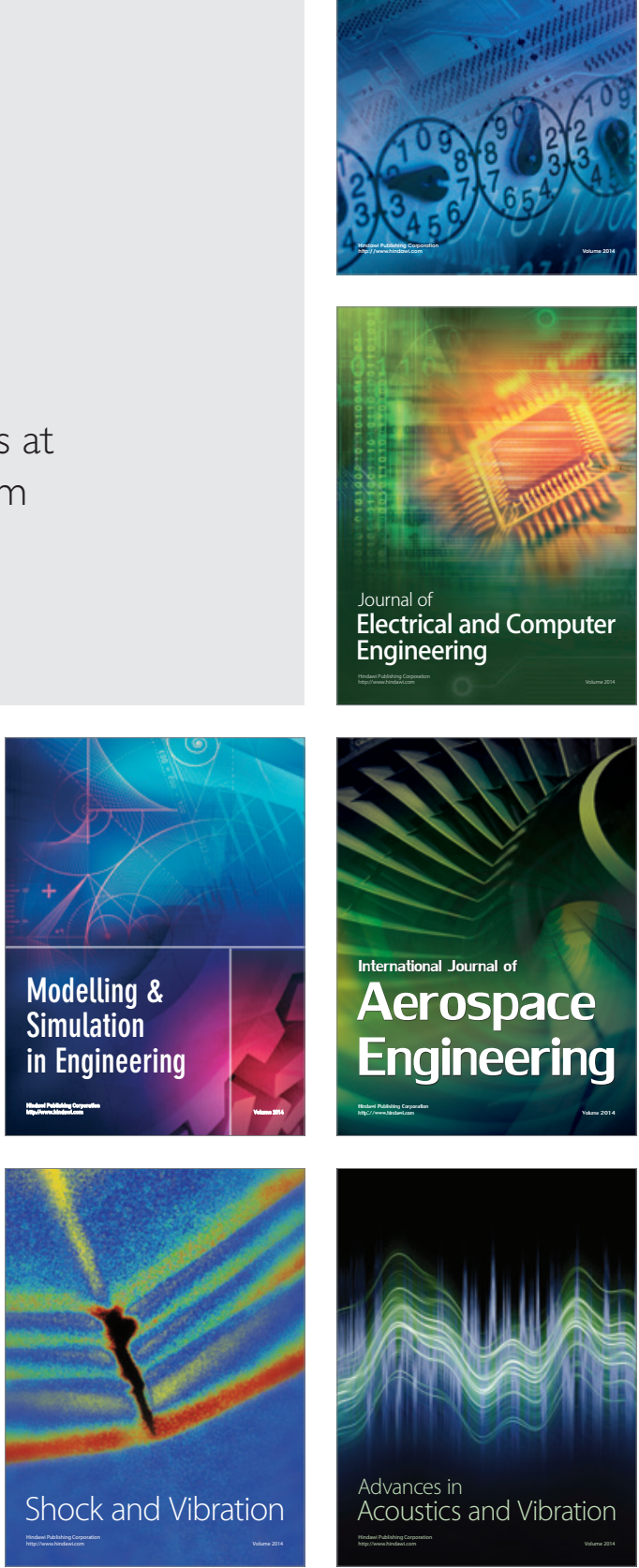